\title{
The Malin cascade in winter 1996
}

\author{
by A. E. Hill ${ }^{1}$, A. J. Souza ${ }^{1,2}$, K. Jones ${ }^{3}$, J. H. Simpson ${ }^{1}$, G. I. Shapiro ${ }^{4}$, \\ R. McCandliss ${ }^{1}$, H. Wilson ${ }^{1}$ and J. Leftley ${ }^{3}$
}

\begin{abstract}
We report evidence for cascading of shelf-edge water down the continental slope northwest of Ireland at $55 \mathrm{~N}$ in February 1996. The measured surface density contrast between shelf-edge and slope waters was $0.01 \mathrm{~kg} \mathrm{~m}^{-3}$ and the resulting dense plume was $20-50 \mathrm{~m}$ thick over the continental slope and penetrated to a depth of $500 \mathrm{~m}$. Cascade waters were warmer but saltier than overlying slope waters and their shelf-edge origin was confirmed by relatively higher chlorophyll concentrations and a distinctive nutrient signature. Other cross-slope transects $100 \mathrm{~km}$ north and south of the cascade site showed dense water at the shelf edge (a situation assumed to be favorable for cascading) but no deep downslope penetration of shelf water. A one-and-a-halflayer dynamical model indicates that the observed downslope penetration of the cascade can be accounted for by the measured excess density of shelf-edge waters even with a realistic level of entrainment of overlying slope waters.
\end{abstract}

\section{Introduction}

Cascades occur when dense water formed on the continental shelf (usually in winter) spills over the shelf edge and descends the continental slope as a gravity current under the influence of friction, entrainment and rotation (Whitehead, 1987). Cascades are of interest because they are a potential mechanism for water exchange at the shelf edge ( Huthnance, 1995). Shelf-edge cascades are most often associated with extreme climatic conditions such as occur on Arctic and Antarctic shelves where winter brine release due to ice growth raises shelf water densities (Gill, 1973; Foster and Carmack, 1976; Melling and Lewis, 1982; Quadfaesel et al., 1988). Outside polar seas, cascading is most commonly associated with semi-enclosed, shallow gulfs subject to arid continental climates where shelf water densities are raised due to salinization by summer evaporation followed by intense winter cooling. This occurs in southern Australia (Tomczak, 1985; Lennon et al., 1987), the Gulf of California (Lavin et al., 1995) and the Adriatic Sea (Zoccolotti and Salusti, 1987; Bignami et al., 1990).

1. School of Ocean Sciences, Marine Science Laboratory, University of Wales, Bangor, Gwynedd, LL59 5EY, United Kingdom.

2. Present address: Division of Applied Sciences, Department of Earth and Planetary Sciences, Harvard University, Cambridge, Massachusetts, 02138, U.S.A.

3. Dunstaffnage Marine Laboratory, P.O. Box 3, Oban, Argyll, PA34 4AD, United Kingdom.

4. P. P. Shirshov Institute of Oceanology, Russian Academy of Sciences, Moscow, Russia. 

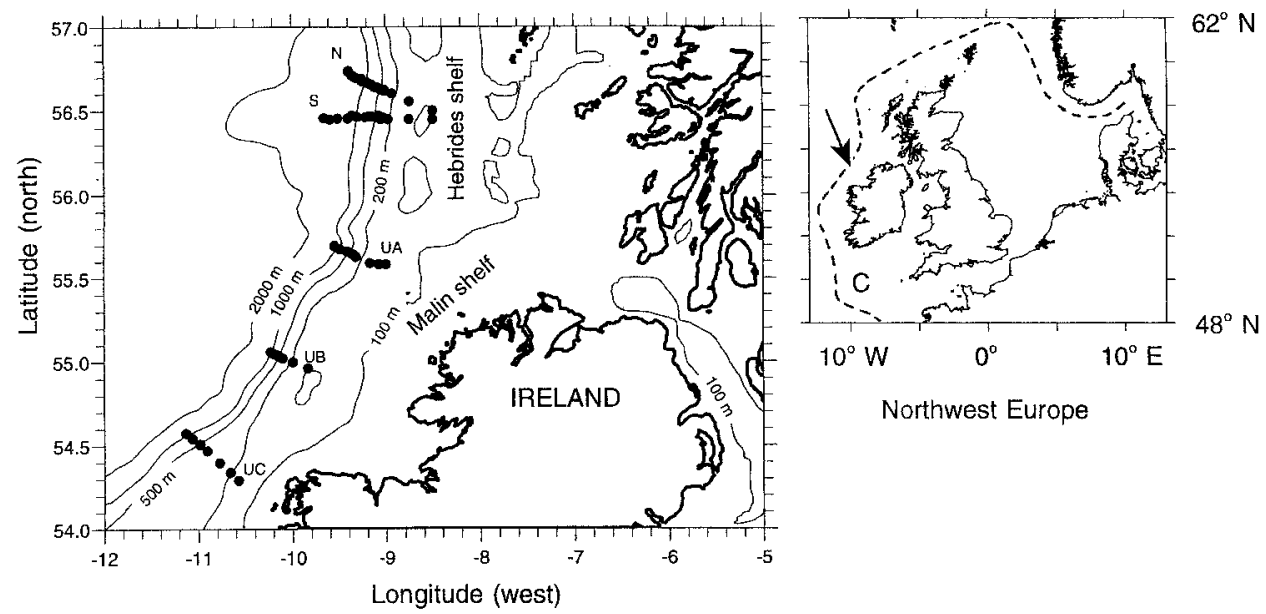

Northwest Europe

Figure 1. Map showing the locations of hydrographic sections. The dashed line on the map of northwest Europe indicates the shelf break at $200 \mathrm{~m}, \mathrm{C}$ indicates the location of the Celtic Sea referred to in the text. The arrow shows the location of the Malin cascade.

Cascading need not always be associated with climatic extremes, however, and fragments of historical evidence point to the possibility that intermittent winter cascading occurs in northwest European waters which are subject to only a relatively mild temperate climate. The proposed mechanism in this location is that, during winter, the depth of convection is limited to less than $200 \mathrm{~m}$ on the continental shelf whereas in the deep waters of the Rockall Trough convection penetrates down to $500 \mathrm{~m}$ or more. Shelf water thus becomes colder (and denser) than adjacent slope waters for the same surface heat loss. Nansen (1913) and Ellett (1968; reviewed by Huthnance, 1995) both suggested that winter cascading might occur over the shallow $(<200 \mathrm{~m})$ Rockall Bank off the western margin of the European shelf. Evidence that Celtic Sea shelf waters (Fig. 1) cascaded down the continental slope in the winter of 1913-14 was presented by Cooper and Vaux (1949). Moreover, several winter observations have shown shelf waters to be denser than over the adjacent continental slope providing circumstantial evidence of conditions favorable for cascading (Cooper and Vaux, 1949; Booth and Ellett, 1983; Turrell, 1996 personal communication). On the eastern side of the European shelf, Ljøen and Svansson (1972) described sudden drops in eastern Norwegian Trench bottom water temperatures, thought to be due to cascading of winter-cooled North Sea water into the Skagerrak .

In this paper we report new observations which, as far as we are aware, provide the first modern evidence for cascading at the northwest European shelf edge. Contrary to expectations for this region, the results show that it is not simply winter cooling, but the relatively higher shelf-edge salinities (due to the presence of the Rockall Slope Current), that are responsible for the buoyancy deficit that leads to cascading. 


\section{Observational methods}

The observations were made during RRS Challenger cruise 125-leg B (13 February 3 March 1996), undertaken as part of the United Kingdom Land Ocean Interaction Study Shelf Edge Study (LOIS-SES). The data presented come from a series of CTD sections (denoted N, S, UA,UB and UC) across the Malin-Hebrides shelf edge northwest of Ireland (Fig. 1). Stations were occupied on the shelf and at nominal $200 \mathrm{~m}$ depth increments down the continental slope. Hydrographic casts were performed with a lowered instrument package consisting of a Neil Brown Mk IIIB CTD equipped with a Chelsea Instruments Aquatrakka Mk II fluorometer, SeaTech transmissometer with $25 \mathrm{~cm}$ path length and a rosette sampler carrying 10 liter General Oceanics Niskin bottles. Dissolved oxygen was measured using a Beckman polarographic oxygen sensor through which water was pumped at a constant rate using a Seabird pump system. The dissolved oxygen sensor was calibrated for each cruise using precise, micro-Winkler determinations (Bryan et al., 1976) made on samples collected throughout the water column. Temperature was calibrated with reversing thermometers and salinity was calibrated from bottle samples taken throughout the cruise. Salinities quoted below were determined using the practical salinity scale and the density anomaly at zero pressure, $\sigma_{t}$, is in units of $\mathrm{kg} \mathrm{m}^{-3}$ (UNESCO, 1981).

Dissolved 'nitrate plus nitrite' $(\mathrm{DN}+\mathrm{N})$, soluble reactive phosphate (SRP), soluble reactive silicate (SRS) and ammonia (DAN) were determined on unfiltered seawater samples immediately after collection using a Lachat Quikchem 8000 flow injection analyser (Lachat Instruments Inc., Milwaukee, WI). The flow injection procedures for these nutrients were similar to those described by Ranger (1994). The chemistries were based on those described by Grasshoff (1976). Detailed descriptions of the procedures are given in the manufacturer's literature (Lachat Quikchem Methods: 31-107-04-1-A; 31-115-01-3-A; 31-114-27-1-A and 31-107-06-1-A for nitrate plus nitrite, phosphate, silicate and ammonia respectively).

During the entire cruise a total of 140 samples were collected from rosette bottles for calibration of the transmissometer. Between 8 and 10 liters of water were filtered through pre-weighed $47 \mathrm{~mm}$ GF/C filters for each sample and used to convert optical beam attenuation measured by the transmissometer into total suspended particulate material (SPM) concentrations. Water was taken from three depths in the upper $100 \mathrm{~m}$ of the water column on each cast for calibration of the fluorometer. Samples $(200 \mathrm{ml})$ were filtered through $25 \mathrm{~mm} \mathrm{GF/F}$ filters which were stored frozen in the dark for approximately 3 weeks prior to analysis. Particulate material retained on the filters was extracted into 90\% acetone and chlorophyll- $a$ concentrations determined using the fluorometric method described by Jones et al. (1984). Regression of these concentrations against respective fluorometer voltage output yielded the relationship, $\ln (\mathrm{Chl})=1.55$ volts -4.20 $\left(r^{2}=0.72, n=224\right)$, between fluorescence and chlorophyll- $a$ which was then applied to all stations. 


\section{Results}

Attention centers on UB-section located at 55N which was sampled on 27 February 1996 (Fig. 1). On this section relatively warm, saline water $\left(>9.725^{\circ} \mathrm{C},>35.4\right)$ was located at the shelf edge and on the upper continental slope (Fig. 2b,c). This high salinity upper slope water is a common feature of the region and is associated with the polewardflowing Rockall Continental Slope Current (Booth and Ellett, 1983; Huthnance, 1986; Hill and Mitchelson-Jacob, 1993). At the surface, this water had an excess density of $0.01 \mathrm{~kg} \mathrm{~m}^{-3}$ over other slope waters (Fig. 2d). Further on-shelf (e.g., station UBS2) and over the outer continental slope, waters were colder and fresher. The most notable feature of the section was the downslope protrusion of warm, saline, dense water which extended to a depth of $500 \mathrm{~m}$ corresponding to a density level of $\sigma_{t}=27.31$. It is this feature that we refer to as the Malin cascade.

The high beam attenuation (Fig. 2e) implies higher levels of SPM in the cascade. The natural interpretation is either that (a) the high SPM of shelf waters acted as a tracer for its downslope motion or (b) material was resuspended from the bed by the downslope movement of dense water or by the poleward-flowing boundary current. Application of the beam attenuation to SPM calibration for the cruise yielded peak values of SPM on the shelf of $0.98 \mathrm{mg} \mathrm{l}^{-1}$ and characteristic values of $0.75 \mathrm{mg} \mathrm{l}^{-1}$ within the cascade. The suspended material thus makes a negligible contribution to the buoyancy of the cascade. Closer inspection of the beam attenuation to SPM calibration on UB section showed the near-bottom cascade waters to be anomalous with respect to other slope stations with considerable scatter about the calibration line. Instead, there was a good correlation $\left(r^{2}=\right.$ 0.8 ) between fluorescence and beam attenuation on this section which suggests that the higher attenuation of the cascade waters was related to biotic rather than to inorganic material. For this reason the transmissometer data for this section have not been converted to SPM but left in the form of beam attenuation (Fig. 2e).

The winter chlorophyll levels (Fig. 2f) were low compared with typical spring values measured in the region $\left(8 \mathrm{mg} \mathrm{m}^{-3}\right)$. Nevertheless, the chlorophyll distribution shows relatively higher levels on the shelf and a tongue of higher chlorophyll protruding downslope similar to the temperature and salinity fields. The chlorophyll distribution provides a diagnostic for the surface origin of cascade waters since light limitation would have prevented in-situ primary biomass production down to depths of 300-500 m. The fact that the high levels of chlorophyll within the downslope protrusion were continuous with the high values on the shelf is consistent with the view that these waters originated on the shelf. The alternative possibility that the observed chlorophyll distribution could have come about by settling out of phytoplankton cells distributed over the surface layers above the continental slope seems much less likely. For instance, there was no evidence of higher surface chlorophyll over the slope at the time of sampling (Fig. 2f) and, in view of the convectively mixed state of these waters, it is also unlikely that primary production took place in surface waters over the slope in the days before UB section was sampled. Although not available from the February 1996 cruise, estimates of phytoplankton settling velocity 
from the Hebrides slope region were obtained on previous cruises (on $\mathrm{N}$ and $\mathrm{S}$ lines). The settling velocity of phytoplankton was determined by chlorophyll-a concentration of samples from a variety of shelf/slope sites removed from a bottom-withdrawal settling tube. In mid-May 1995, surface samples gave a median settling velocity of $0.02( \pm 0.0007)$ $\mathrm{m} \mathrm{day}^{-1}$ with $71 \%$ of the population settling at a rate less than $0.1 \mathrm{~m}^{\text {day }}{ }^{-1}$ and $91 \%$ at less than $1 \mathrm{~m} \mathrm{day}^{-1}$. The concentration of chlorophyll in these samples was from 0.7 to $5.4 \mathrm{mg} \mathrm{m}^{-3}$. Summer phytoplankton samples gave a median settling velocity of 0.037 $( \pm 0.006) \mathrm{m}_{\text {day }}{ }^{-1}, 84 \%$ settling slower than $1 \mathrm{~m}^{2}$ day $^{-1}$ with chlorophyll concentrations between 1 and $1.8 \mathrm{mg} \mathrm{m}^{-3}$. On this basis, it would take at least 500 days for phytoplankton to settle from surface waters to the $500 \mathrm{~m}$ isobath on the slope. It is, therefore, unlikely that the relatively high chlorophyll concentration protruding down the slope was due simply to the settling of phytoplankton under their own gravity. The possibility that the observed high chlorophyll waters were advected alongslope in the Rockall Slope Current is not supported by the chlorophyll distribution farther south on UC section which does not show high concentrations at depth over the slope. Neither does alongslope advection solve the problem of how chlorophyll reached these depths originally. Moreover, in a later section we argue on dynamical grounds that cascade waters descend the slope to $500 \mathrm{~m}$ relatively quickly ( $<2$ days). The speed of the Rockall Slope Current $\left(0.1 \mathrm{~m} \mathrm{~s}^{-1}\right)$ and the alongslope density driven motion of the cascade implies an alongslope translation distance in this time of just a few tens of kilometers at most, which in turn suggests a local shelf-edge source for the dense waters observed protruding down the slope. The conclusion is that the obvious interpretation of Figure $2 \mathrm{f}$ is correct, namely that the high chlorophyll tongue which protrudes downslope has its origin on the shelf and that the chlorophyll acts as a tracer for downslope movement of shelf-edge waters.

Figure 3 shows a more detailed view of the cascade for which properties have been contoured in space with the vertical coordinate as height above the bed. Stations are given equi-distant spacing in Figure 3 in order to stretch the horizontal scale of the slope portion of the section with respect to the more widely spaced shelf stations. The penetration of the cascade to station UB500 is clear. The density section (Fig. 3a ) shows the tightest vertical gradients bounded above by the $\sigma_{t}=27.315$ isopycnal with wider spacing between this and the $\sigma_{t}=27.310$ contour. The body of the plume thus seems to be about 20-50 m thick over the slope. However, the density and other tracer fields show evidence of cascade waters up to $150 \mathrm{~m}$ above the bed (Fig. 3). The relatively high dissolved oxygen in the cascade (Fig. $3 \mathrm{f}$ ) provides further confirmation of the recent surface origin of these waters.

Superimposed on the density section (Fig. 3a ) are the positions (solid circles) at which water samples were taken for nutrient analysis. At UB300, UB400 and UB500 only the bottom bottles were unambiguously within the cascade. On the nitrate-silicate diagram (Fig. 4a), waters at the most inshore shelf station (UBS2) were low in both nitrate and silicate and consequently appear at the bottom left hand corner of the diagram. In contrast, the deep waters (beneath the thermocline below $500 \mathrm{~m}$ depth) at stations UB750 and UB1000 had high nitrate and silicate values and occupy the extreme top right of the figure. 

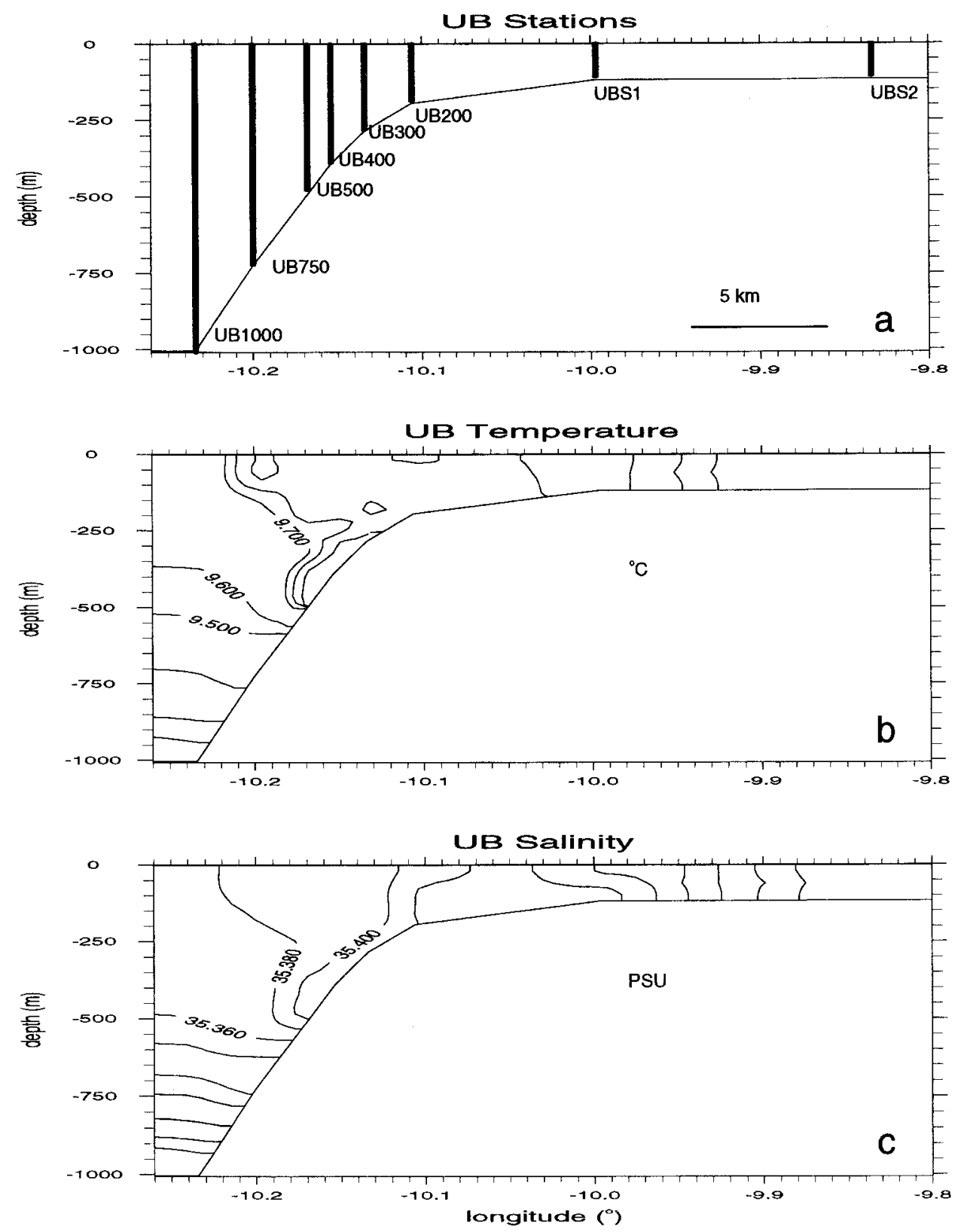

Figure 2. Hydrographic sections at the UB line northwest of Ireland (55N), 27 February 1996.

Surface and mid-depth waters between UB1000 (at the western end of the slope) and UBS1 (shelf) formed a cluster centered on nitrate and silicate concentrations of $7 \mu \mathrm{mol} \mathrm{l}^{-1}$ and $4.5 \mu \mathrm{mol} \mathrm{l}^{-1}$ respectively. Between the innermost shelf waters (UBS2) and the latter cluster were waters from (a) the bottom 3 bottles (depths 57, 97 and $107 \mathrm{~m}$ ) from the shelf station 

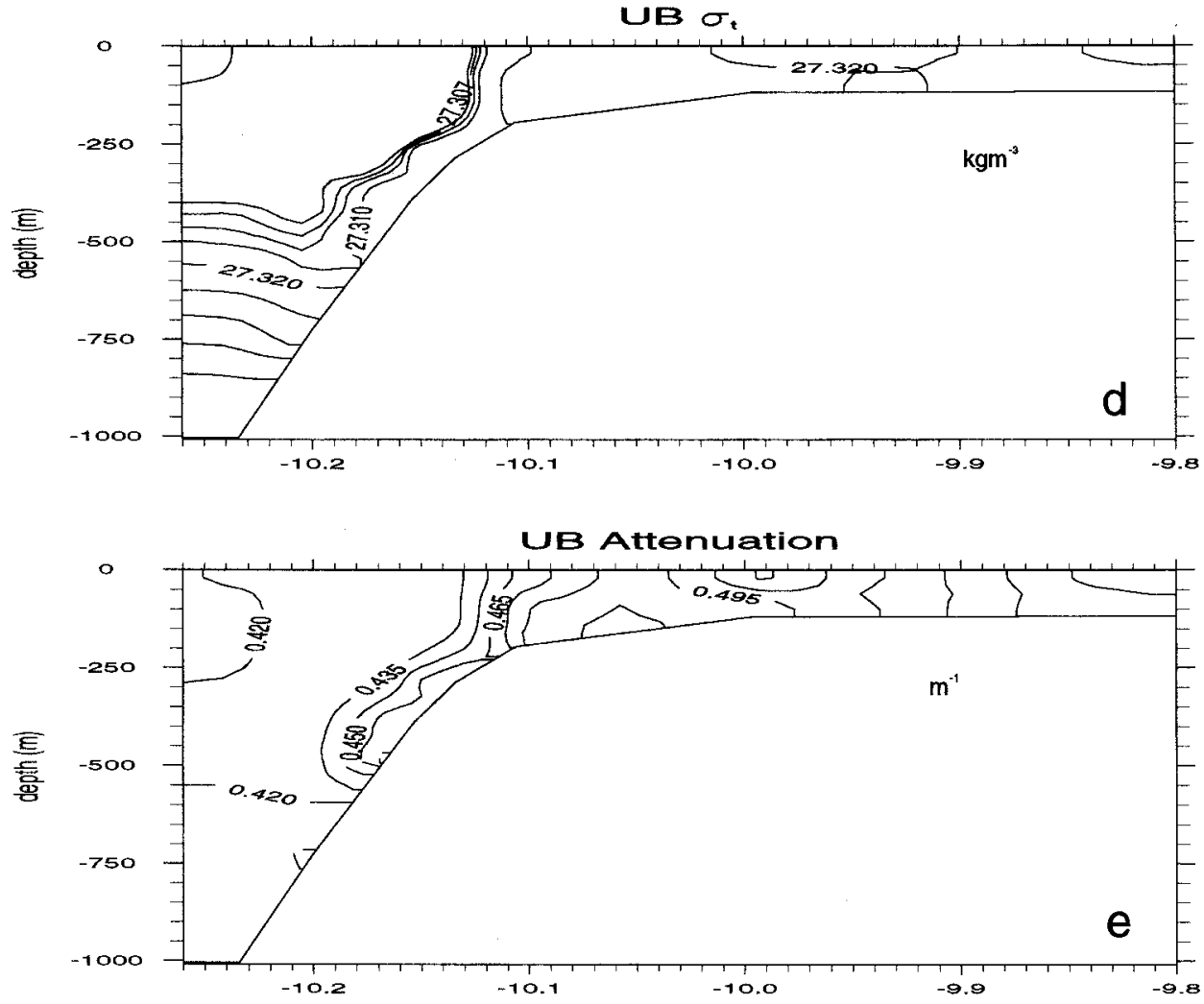

UB Chlorophyll

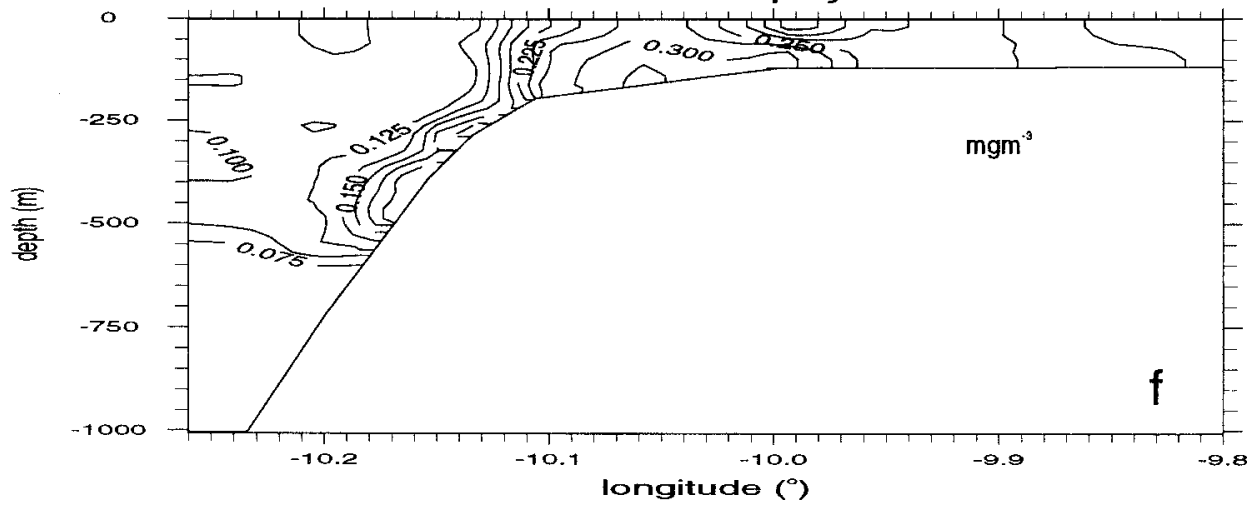

Figure 2. (Continued)

UBS1 (closest to the shelf edge), (b) the waters from station UB200 at the shelf break and, most notably, (c) the waters obtained from the bottom bottles on each of stations UB300, UB400 and UB500 (cascade waters). Bottom waters on the slope (as far as station UB500) thus had a nitrate-silicate signature which was intermediate between that of shelf water and 

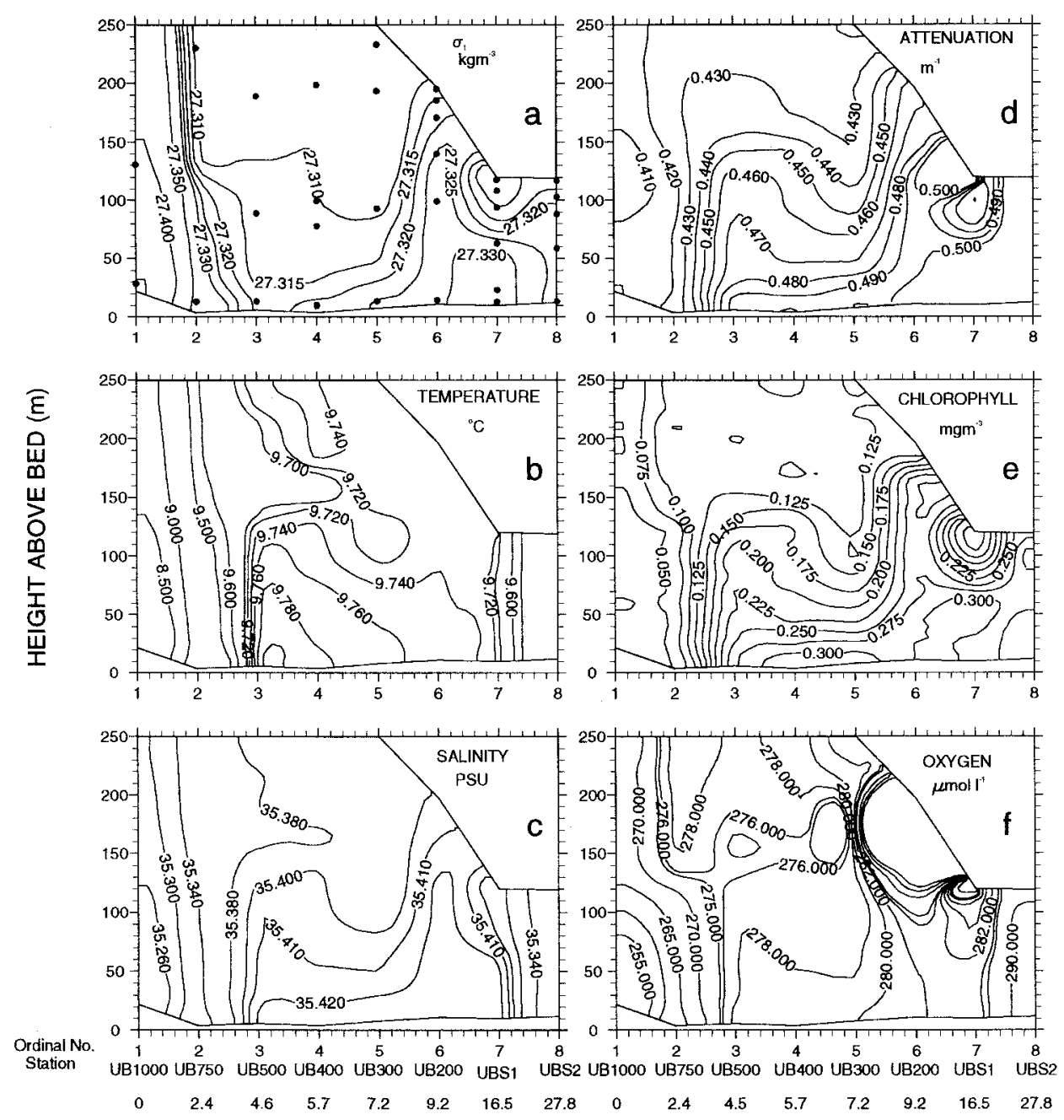

\section{DISTANCE (km)}

Figure 3. Properties on UB section sampled on 27 February 1996 contoured against height above the seabed showing (a) density $\left(\sigma_{t}\right)$, (b) temperature ${ }^{\circ} \mathrm{C}$, (c) salinity (practical salinity scale), (d) transmissometer beam attenuation $\left(\mathrm{m}^{-1}\right)$, (e) chlorophyll concentration $\left(\mathrm{mg} \mathrm{m}^{-3}\right)$, (f) dissolved oxygen $\mu \mathrm{mol} \mathrm{l}^{-1}$. Stations are shown with equidistant spacing in order to exaggerate the horizontal scale over the continental slope. Station names are indicated at the bottom of the figure along with the distance $(\mathrm{km})$ from station UB1000. The solid line near the bottom of each panel shows the height above the seabed to which the CTD was lowered. The solid line near the top right of each panel shows the location of the sea surface. The solid circles in Figure 3a show the positions at which water samples were taken for nutrient analysis. 

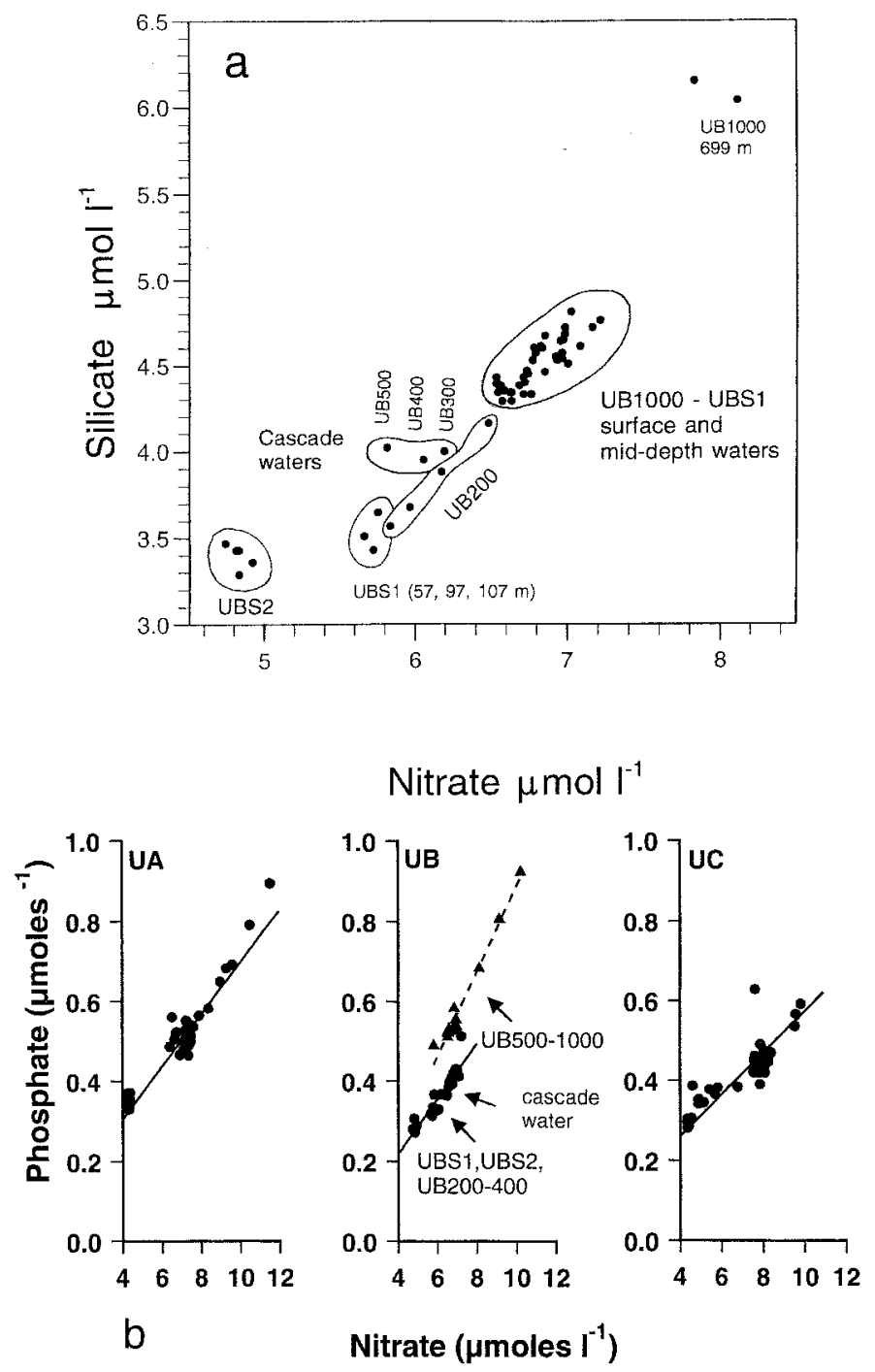

Figure 4. (a) nitrate-silicate diagram for UB section. 'Cascade waters' are those obtained from the bottles nearest to the seabed (Fig. 3a) on stations UB300, UB400 and UB500, (b) nitrate-phosphate diagrams for sections UA, UB and UC. The statistics of the mixing lines shown are: UA section, $\mathrm{y}=0.0654 \mathrm{x}+0.0437, \mathrm{r}^{2}=0.0896, \mathrm{df}=52$; UB section (shelf and upper slope, solid line), $\mathrm{y}=$ $0.0692 \mathrm{x}-0.0592, \mathrm{r}^{2}=0.877, \mathrm{df}=24$; UB section (lower slope, dashed line), $\mathrm{y}=0.1068 \mathrm{x}$ $0.1790, \mathrm{r} 2=0.973, \mathrm{df}=14$; UC section (lower slope, dashed line), $\mathrm{y}=0.0523 \mathrm{x}+0.051, \mathrm{r} 2=$ $0.809, \mathrm{~d}_{\mathrm{f}}=52$ where $\mathrm{y}$ and $\mathrm{x}$ refer to phosphate and nitrate concentrations $\left(\mu \mathrm{mol} \mathrm{l}^{-1}\right)$ respectively.

overlying slope waters. The nitrate-phosphate diagrams (Fig. 4b) illustrate the anomalous character of UB section (the cascade site) with respect to the other cross-slope sections (Fig. 1). The shelf sections and those over the upper continental slope (between UB200 and UB400 inclusive) fall on a mixing line (solid line) that is distinct from the remaining 
deeper slope waters at UB500 and UB1000 (dashed line). This separation of mixing lines, indicating a significant mixture of shelf water, is not present on either UA or UC sections The position of the 'cascade water' from the bottom bottles on stations UB300 and UB400 is indicated on the diagram. The bottom bottle at station UB500 is the lowermost triangle on the upper (dashed) mixing line for UB section. The nutrient data thus supplement the inference from the chlorophyll section, that the cascade waters were composed partly of shelf-edge waters (like UB200 and UBS1).

Four other CTD sections along the Malin-Hebrides shelf-edge were sampled during the Challenger 125-B cruise. At sections N and S (Fig. 1) shelf water was less dense than slope water and hence conditions were unfavorable for cascading (Fig. 5a,b). On section UA, $100 \mathrm{~km}$ alongslope to the north of $\mathrm{UB}$, an isolated body of dense water was present at the shelf-edge but there was no indication of downslope penetration of this water (Fig. 5c). On UC section, $100 \mathrm{~km}$ alongslope to the south of the UB, there was denser water on the upper slope with some indication of downslope protrusion of these waters (Fig. 5d). The depth of penetration $(300 \mathrm{~m})$ of dense water was less than on UB section, probably on account of the gentler bottom slope (Fig. 5d). Cascading was thus spatially restricted along the MalinHebrides slope in February 1996 with cascading-favorable conditions found over an alongslope distance of $\sim 200 \mathrm{~km}$ (sections UA, UB and UC). Only on section UB, however, was there clear evidence of substantial downslope penetration of shelf-edge waters. In all cases where dense shelf-edge waters were found, it was their relatively higher salinity that was responsible for the density excess.

\section{Dynamical models of the Malin cascade}

Although we have provided evidence that shelf water was transported downslope to a depth of $500 \mathrm{~m}$ on the Malin slope, nothing has been said of how this occurred. Two candidate mechanisms are relevant. Firstly, the buoyancy deficit of shelf-edge waters could simply have driven them downslope as a gravity current (density-driven cascade) subject to the modifying influences of friction, rotation and entrainment. However, we also know that a slope-trapped boundary current flows poleward along the Malin-Hebrides upper slope, hence the second possibility is that (if this current were to impinge directly on the seabed) water would be forced downslope in a bottom Ekman layer (forced Ekman drainage). This mechanism would operate even in the absence of a density difference between shelf and slope waters but clearly relatively higher shelf densities would assist the ensuing downslope motion. Since we have no measurements of the Slope Current at UB section, our approach below is to make use of the observations that we do possess to address the question of whether the gravity current hypothesis is sustainable.

It is not obvious a priori that the observed surface density contrast between shelf-edge and slope waters on UB section $\left(0.01 \mathrm{~kg} \mathrm{~m}^{-3}\right.$, Fig. $\left.2 \mathrm{~d}\right)$ was sufficient to drive a cascade in the form of gravity current downslope to the observed depth of $500 \mathrm{~m}$, particularly in view of the fact that the plume would probably entrain overlying, lighter slope waters during at least part of its descent. To assess this further we initially applied a standard streamtube 

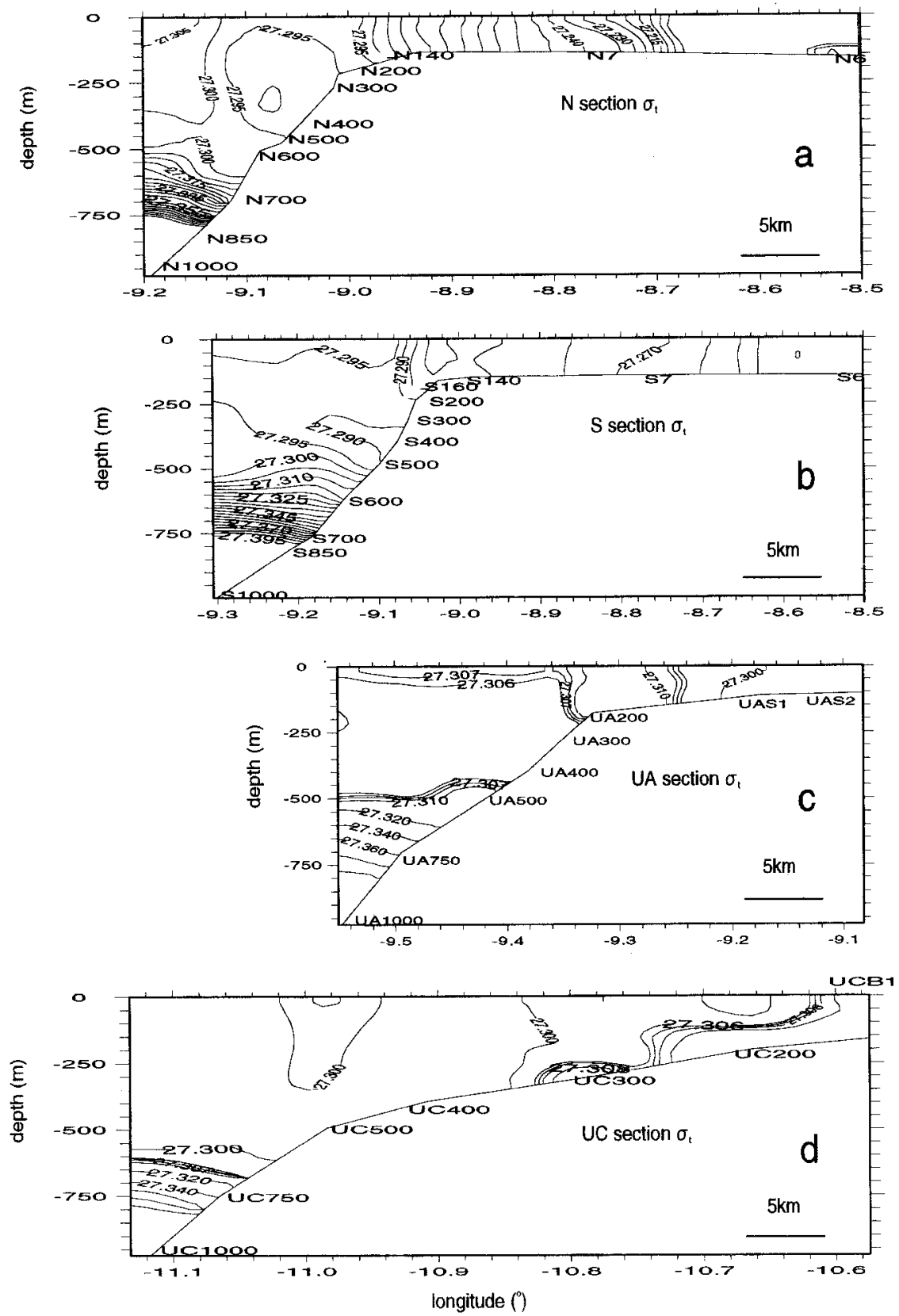

Figure 5. Density $\left(\sigma_{t}\right)$ measured on the transects shown in Figure 1: (a) N (20-21 February 1996), (b) S (14 and 18-20 February 1996), (c) UA (26-27 February 1996), (d) UC (27-28 February 1996). 
model (Smith, 1975; Killworth, 1977). These results are described briefly below before moving on to the application of a more recent model developed by Shapiro and Hill (1997) which incorporates the internal dynamics of dense plumes and so overcomes some of the limitations of the streamtube approach.

The streamtube formulation followed that of Killworth (1977) and the governing equations are not repeated here. The following upstream values of streamtube parameters were used: initial descent angle relative to isobaths, $90^{\circ}$, initial plume thickness, $50 \mathrm{~m}$, alongstream cross-sectionally averaged velocity, $v=0.01 \mathrm{~m} \mathrm{~s}^{-1}$. We arbitrarily assumed that the dense water source was fairly localized (i.e., extended one quarter of the distance to the neighboring sections UA and UC), giving an initial upstream plume width of $50 \mathrm{~km}$ and upstream cross-sectional area of $5 \times 10^{5} \mathrm{~m}^{2}$. Based on Figure 2, the upstream plume water was taken to be $0.025^{\circ} \mathrm{C}$ warmer than the slope waters and with an excess salinity of 0.02 , giving an upstream excess density of $0.011 \mathrm{~kg} \mathrm{~m}^{-3}$. The ambient density over the entire slope region was taken to be represented by the profile at station UB 1000 which is reasonable because, apart from the perturbation produced by the cascade itself, isopycnals are relatively flat from station UB1000 into the slope. (Fig. 2). On account of deep winter convection, slope waters above $500 \mathrm{~m}$ are fairly homogeneous so the practical effect of the above specification of ambient density is to define the neutral density level rather than to alter significantly the buoyancy of the plume with respect to the ambient fluid during its descent of the slope. The continental slope steepness was taken to be constant with a value of $800 \mathrm{~m} / 8.6 \mathrm{~km}=9.26 \times 10^{-2}$ (Fig. 2 ).

There is more uncertainty concerning the values of the friction and entrainment coefficients. Friction in the streamtube model is represented by a quadratic drag law (Smith, 1975; Killworth, 1977). The widely accepted value for the bottom quadratic drag coefficient in shallow seas is $k_{b}=0.0025$. However, in all cases, where this value was used it was impossible to get the plume to descend to a depth greater than $350 \mathrm{~m}$ before it was deflected by rotation to follow isobaths (descending the slope only very slowly thereafter). However, in problems concerning flow of dense water down slopes it is common to use the much higher value, $k_{b}=0.03$ (e.g., Dietrich, 1956; Steele, 1959; Bowden, 1960; Smith, 1975; Killworth, 1977). We used both the conventional and higher values of $k_{b}$ when the Malin cascade. The physical basis for the higher value of $k_{b}$ is not clear but it is probably related to the fact that the quadratic drag law assumed in the streamtube formulation (Killworth, 1977) distributes friction over the entire plume and so probably underestimates frictional effects for thick plumes.

Two methods were used to estimate the unknown entrainment coefficient. Physically, the most desirable approach is to allow the entrainment coefficient to be determined by the dynamics of the plume itself. For this purpose we first employed the entrainment parameterization of Price and Baringer (1994) for which entrainment increases with increasing plume velocity and depends upon an overall Richardson number. The effect of entrainment on the modeled plume was assessed by the evaluation of the 'slope water 
fraction' of plume tracers defined by

$$
\Sigma=\left(\frac{C_{\text {plume }}-C_{\text {shelf }}}{C_{\text {slope }}-C_{\text {shelf }}}\right) \times 100 \%
$$

where $C_{\text {slope }}, C_{\text {shelf }}$ and $C_{\text {plume }}$ are conservative tracer (e.g., temperature, salinity or nutrients) concentrations in ambient slope water, continental shelf water and within the cascade plume, respectively. The above quantity ranges from 0 when the plume is composed entirely of shelf water to $100 \%$ when it is composed entirely of slope water. The nutrient diagram (Fig. 4a) and other tracers (Fig. 3) indicate that Malin cascade waters lay approximately midway between shelf and outer slope waters on the mixing line so the implied $\Sigma$ is of the order of $50 \%$.

Low friction $\left(k_{b}=0.0025\right)$ promotes higher plume velocities and hence greater entrainment so that when the Price and Baringer form of entrainment was used, it was found that the final plume value of $\Sigma$ was about $50 \%$. However, in this case the plume did not descend deeper than $350 \mathrm{~m}$ in contradiction to the observations; the predicted descent time to this depth was 8 hours. On the other hand, high friction $\left(k_{b}=0.03\right)$ enabled the plume to descend to $500 \mathrm{~m}$ (in 2 days) but entrainment was much lower on account of the lower plume speed and the end-point value of $\Sigma$ was only $10 \%$. The model thus highlights the interesting inconsistency that it is not possible to explain both the final plume depth and the implied level of entrainment (from the tracer concentrations) in terms of a physically reasonable parameterization of entrainment in terms of plume dynamics. No doubt improvements to the fit could be made by fine tuning of the entrainment parameterization but this would add little new knowledge. To examine the implied level of entrainment, we simply set the entrainment coefficient constant over the entire trajectory and adjusted its value to give $\Sigma \sim 50 \%$ at the neutral density level. With friction set at $k_{b}=0.03$, the plume reached a depth of $480 \mathrm{~m}$ in 4.5 days with a final value of $\Sigma=50 \%$ when the entrainment coefficient was $E=0.0025$.

\section{a. One and a half layer model}

To overcome some of the problems with the streamtube approach we have used a model which incorporates a more detailed description of the internal dynamics of a dense plume on a slope including a more realistic representation of friction. The model is described in detail by Shapiro and Hill (1997) but a brief outline of its main features is provided below. A homogeneous bottom layer of dense fluid is assumed. This is overlain by a finitethickness upper layer which is much thicker than the Ekman layer scale. In view of the fact that slope waters were fairly homogeneous above the neutral density level this assumption is reasonable (Fig. 2). The upper layer is static although in principle an upper layer geostrophic flow (e.g., Rockall Slope Current) can be imposed (one and a half layer approximation). The bottom topography is arbitrary although only a purely twodimensional slope (using the topography shown in Fig. 2a) is considered in the present application. 
The height of the seabed above an arbitrary horizontal datum line is $b(x, y)$ and the lowerlayer thickness (i.e., the height above the bed of the interface between upper and lower layers) is $h(x, y, t)$. The density of the bottom layer is $\rho$ and the reduced gravitational acceleration is $g^{\prime}=g \Delta \rho / \rho$, where $g$ is the gravitational acceleration and $\Delta \rho$ is the density difference between layers. Steady, linearized momentum equations in the lower and upper layers are assumed and include earth rotation, an internal pressure gradient due to interface slope (which acts in the lower layer only) and internal friction parameterized in terms of a constant vertical eddy viscosity $N_{z}$ (Shapiro and Hill, 1997). The boundary conditions are no slip at the sea bed, continuity of velocity and stress at the interface, and stress tending to zero with increasing height above the bed in the upper layer. The momentum equations themselves are steady and linear, so the time dependence and nonlinearity of the plume evolution are introduced when these are combined with the mass conservation equation for the lower layer to derive a governing equation for the time-evolution of the lower layer thickness (Shapiro and Hill, 1997). Physically, the friction terms introduce departures from geostrophy bringing about flow convergence/divergence within the bottom layer and near the density interface; this in turn causes the bottom layer thickness to evolve with time. Following the notation of Shapiro and Hill (1997), the governing equation is

$$
\frac{\partial h}{\partial t}+\left(R_{1} \boldsymbol{u}_{\boldsymbol{B}}^{S}+R_{3} \boldsymbol{u}_{\boldsymbol{B}}\right) \cdot \nabla h=\frac{g^{\prime} h_{E}}{f} \nabla\left(R_{6} \nabla h\right)+R_{6} \frac{g^{\prime} h_{E}}{f} \nabla^{2} b+w_{e}
$$

where $\nabla$ is the horizontal gradient operator and $f$ is the Coriolis parameter. This has the form of a nonlinear advection-diffusion equation for interface thickness. The velocity vectors $\boldsymbol{u}_{\boldsymbol{B}}$ and $\boldsymbol{u}_{\boldsymbol{B}}^{S}$ both have magnitude $u_{B}=g^{\prime} / f|\nabla b|$ and are directed alongslope (with shallow water to the right in the northern hemisphere) and downslope respectively. Here $u_{B}$ is the Nof speed which is the speed of frictionless, alongslope translation under the influence of earth rotation of a dense water mass with reduced gravity, $g^{\prime}$ (Nof , 1983). The functional form of the coefficients $R_{1}, R_{3}$ and $R_{6}$ is

$$
\begin{aligned}
& R_{1}(\eta)=2 Q(\eta)-Q(2 \eta), \quad R_{3}(\eta)=2 P(\eta)-P(2 \eta), \\
& R_{6}(\eta)=P(\eta)-Q(\eta)+1 / 4(Q(2 \eta)-P(2 \eta)), \\
& P(\eta)=1-\cos (\eta) e^{-\eta}, \quad Q(\eta)=\sin (\eta) e^{-\eta}
\end{aligned}
$$

where $\eta=h / h_{E}$ and $h_{E}=\left(2 N_{z} / f\right)^{1 / 2}$ is the Ekman depth (Shapiro and Hill, 1997). Physically, the second term on the left-hand side of Eq. (2) represents the advective evolution of the interface in response to buoyancy forcing. The important terms on the right-hand side of Eq. (2) are the first one, which is a diffusion-like term representing the frictional spreading of the interface in response to Ekman convergence/divergence near the bottom and interfacial boundary layers, and the last term which represents the thickening of the lower layer by entrainment of upper layer fluid with entrainment velocity $w_{e}$. The reduction of the 
density contrast between the plume and ambient fluid due to entrainment is given by

$$
\frac{d g^{\prime}}{d t}=-\frac{g^{\prime}(t)}{V(t)} \frac{d V}{d t}
$$

where $V$ is the integrated volume of that part of the plume over the continental slope (i.e., between the leading edge of the plume and the shelf break). This relation assumes that entrained fluid is mixed uniformly throughout the plume. Although more sophisticated in its formulation, overall the dynamics of the one-and-a-half layer and the streamtube models are similar in that they are ultimately controlled by the interplay between just three forces: buoyancy, friction and the Coriolis force.

The model was run with a static upper layer (i.e., no barotropic forcing such as a slope current). The objective was to examine whether it would be possible, given the initial density contrast and the overall level of entrainment, for the plume to penetrate to a depth of $500 \mathrm{~m}$ downslope. The initial density contrast between the plume and overlying waters was taken as $\Delta \rho=0.01 \mathrm{~kg} \mathrm{~m}^{-3}$. There are two adjustable parameters in the model, the Ekman depth and the entrainment velocity. The Ekman depth was taken to be $h_{E}=10 \mathrm{~m}$, chosen in accordance with observations to give a fully developed thickness at the nose of the plume of $20 \mathrm{~m}$ (characteristically two Ekman depths as discussed by Shapiro and Hill (1997)). The entrainment velocity was set as $w_{e}=2.5 \times 10^{-4} \mathrm{~m} \mathrm{~s}^{-1}$ which gave a final value of the slope water fraction, $\Sigma=46 \%$. The model does not incorporate ambient stratification and so there is no neutral density level as such. The simulation was therefore terminated once the leading edge of the plume reached a depth of $500 \mathrm{~m}$, the known neutral density level at this site. With the above parameters the dense plume was found to reach this depth after 1.5 days. Figure 6 shows the interface height above the bottom of the plume at $t=1.5$ days (thick line) superimposed upon the observed density section (shown previously in Fig. 3a). Subject to the above parameters, the simulation reasonably reproduces the thickness of the plume. The conclusion is that with the initial (observed) plume density deficit and a level of entrainment consistent with the observed dilution, it is possible for the plume to reach a depth of $500 \mathrm{~m}$ for a realistic level of friction $\left(h_{E}=10 \mathrm{~m}\right)$. Buoyancy forcing alone thus accounts for the descent depth of the cascade and hence it is not necessary to invoke any additional forms of forcing (such as Slope Current forced Ekman drainage). The improved representation of friction in the one-and-a-half layer model means that the undesirable use of an unusually high friction coefficient in the streamtube approach has been avoided.

\section{Discussion}

Three questions are raised by our observations. Firstly, is what we have observed indeed a 'cascade' in the sense of a density-driven plume, or was the downslope penetration of shelf water forced by some other process? Secondly, by what mechanism did shelf water originally become denser than slope water? Thirdly, how extensive is cascading at the European shelf edge and what are its likely effects? 


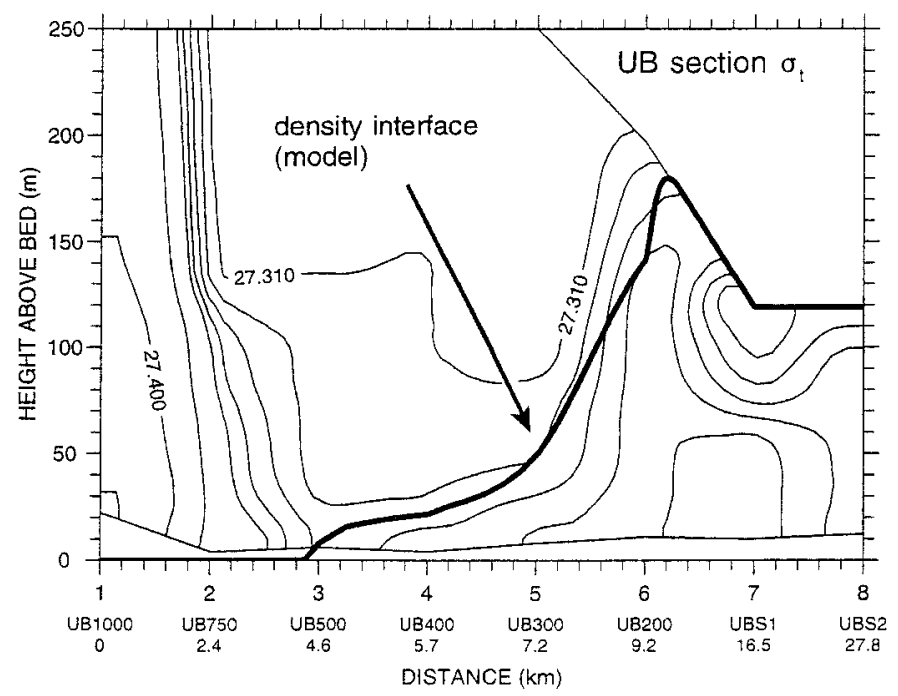

Figure 6. Results from the one-and-a half layer model of Shapiro and Hill (1997) showing the height above the seabed of the interface between the bottom and upper layers at $t=1.5$ days after the initial state. The bottom topography used is the same as that shown in Figure 2a. The initial condition was that the density interface was approximately vertical at station UB200 and the density contrast between layers was $0.01 \mathrm{~kg} \mathrm{~m}^{-3}$. The entrainment velocity was set at $w_{e}=$ $2.510^{-4} \mathrm{~m} \mathrm{~s}^{-1}$ which gave a slope water fraction $\Sigma=54 \%$ at $t=1.5$ days. The modeled density interface is shown superimposed on the measured density field on UB section (Fig. 3a).

In answer to the first question we have argued above that the excess buoyancy of Malin shelf-edge waters was sufficient to account for the observed penetration depth of the cascade and that consequently no other forcing mechanism is required to explain the observations. Nevertheless, was it possible that other downslope forcing mechanisms were also in operation? We have no direct measurements of the Slope Current at the cascade site but measurements made further north on $\mathrm{N}$ and $\mathrm{S}$ sections (Fig. 1) as part of the LOIS-SES study suggest that the Slope Current core may be detached from the seabed over the slope below $400 \mathrm{~m}$, a situation which would not favor downslope Ekman drainage. On the other hand, the continental slope is particularly steep at UB section (Fig.1) and, because to first order it is topographically steered, the Slope Current might therefore be expected both to intensify at this location and impinge on the upper slope seabed. This would promote Slope Current forced Ekman drainage in the vicinity of UB section.

Shapiro and Hill (1997) have examined the issue of the relative importance of buoyancy effects and downslope forced Ekman drainage in driving the downslope motion on a continental slope. Their conclusion is summarized by the ratio of the influence of cascading to Ekman drainage given by

$$
\frac{u_{c}}{u_{E}} \sim \frac{2 g^{\prime} S}{f v_{0}}
$$


which derives from a generalized form of Eq. 2 which includes an upper layer geostrophic current. Here $S$ is the bottom slope, $u_{c}$ is the downslope speed due to pure density-driven cascading, $u_{E}$ is the downslope Ekman drainage velocity forced by an overlying alongslope current of speed $v_{0}$. For the Malin slope at $55 \mathrm{~N}$, assuming a characteristic Slope Current speed of $0.1 \mathrm{~m} \mathrm{~s}^{-1}$ (Huthnance, 1986) and all other variables with their previous values, it is found that $u_{c} / u_{E} \sim 2$. Thus the influence of cascading is expected to be twice that of Ekman drainage. The above relation illustrates that a steep bottom slope favors cascading and that Ekman drainage will be relatively more important over gentle slopes. Whether or not Ekman drainage makes a significant contribution to motion on the continental slope itself, the process may be relevant to the initiation of cascading. This is because at the top of the slope and on the outer shelf (where bottom slope is small) a means is required to move dense water to the shelf break where buoyancy forces can then take over as the dominant downslope driving mechanism. In addition to steady Ekman drainage, other unsteady processes such as continental shelf waves (Middleton et al., 1982; Huthnance, 1986) and shelf edge eddies (Huthnance, 1986, 1995; Holligan and Groom, 1986) may also be responsible for moving dense water to the shelf break prior to cascading.

We next turn to the question of how shelf-edge water came to be denser than slope water. The simplest mechanism is that, for the same winter surface heat loss, shallow shelf waters (where the convection depth is limited by the seabed) become cooler than deeper slope and ocean waters (Nansen, 1913; Cooper and Vaux, 1949). However, the situation observed on UA, UB and UC sections, was not so straightforward since Figure 2 shows that it was the excess salinity of shelf-edge waters that gave rise to the buoyancy deficit of shelf edge waters. These saline waters originate from the poleward flowing Slope Current (Hill and Mitchelson-Jacob, 1993). During summer, Slope Current water is warmer, saltier and more buoyant than adjacent waters both on the shelf and in the Rockall Trough to the west (Booth and Ellett, 1983; Hill and Mitchelson-Jacob, 1993) and cascading cannot occur. As the region is cooled in winter, however, the temperature difference between Slope Current and adjacent waters is reduced and the high salinity of the Slope Current becomes the controlling influence on density. Indeed, the nonlinearity of the equation of state can accentuate this effect. On the $T-S$ (temperature-salinity) diagram, isopycnals are more widely spaced at lower values of $T$ and $S$. Thus, if warm, saline (Slope Current) waters and colder, fresher (Rockall Trough) waters, initially of the same density, are cooled by the same amount, the higher salinity Slope Current waters will acquire a relatively higher density. The magnitude of this effect is illustrated by the following example characteristic of Malin shelf-edge/slope waters: Consider waters with $\left(T, S, \sigma_{t}\right)$ values of $\left(10.0^{\circ}\right.$ $\mathrm{C}, 35.3,27.187)$ and $\left(10.445^{\circ} \mathrm{C}, 35.4,27.187\right)$ characteristic of the Rockall Trough and Slope Current surface waters respectively. Cooling of $2^{\circ} \mathrm{C}$ applied to both water types (with salinities unchanged) results in densities $\left(\sigma_{t}\right)$ of 27.51 and 27.52 respectively, a density difference comparable with the observed surface density contrast in the Malin cascade. It is clear that the incursion of Slope Current water onto the shelf was an important pre-requisite for cascading in this case. In other documented cases of cascading world-wide, the dense 
water is formed locally on the shelf by cooling or salinization due to evaporation or freezing. The Malin cascade, on the other hand, points to a new mechanism in which a poleward-flowing boundary current supplies saline waters to the shelf which go on to form dense shelf-edge waters after winter cooling.

With the available observations, any answer to how spatially and temporally extensive winter cascading is at the northwest European shelf-edge must remain speculative at present although the long temperature time series of Ljøen and Svannson (1972) from the Skagerrak give an indication of the intermittency of the phenomenon. The only previously documented observations of cascading at the shelf-edge west of the British Isles were made on the Celtic Sea slope (Cooper and Vaux, 1949; Fig. 1) and the present results thus extend the geographical range of observed European shelf-edge cascading. Whereas the Celtic slope is cut by numerous deep canyons which might be expected to favor downslope movement of heavy shelf water, this is not the case on the Malin-Hebrides slope which has a much smoother topography. A distinctive feature of the Malin slope topography at the UB section which may have favoured downslope motion is the exceptionally steep bottom slope in which the isobaths between 200 and $500 \mathrm{~m}$ are more closely spaced than almost anywhere else west of Ireland or Scotland. A steep slope would favour downslope density-driven cascading and might also intensify the Slope Current (by topographic steering) and cause it to impinge on the upper slope. Both of the latter effects would promote enhanced downslope Ekman drainage at this site. A second feature which may also be relevant is that the continental slope steepens rapidly in the poleward direction upstream of UB section (note the convergence of the isobaths between 200 and $500 \mathrm{~m}$ in Fig.1). In this context it is interesting to note that Hill (1995) has argued that an alongslope current will tend to leak onto the continental shelf at locations where slope steepness increases suddenly in the direction of flow. The implication, therefore, is that saline Slope Current water may be more prone to come onto the shelf at this location, thereby providing favorable conditions for dense water formation. Aside from this, spreading of the Slope Current onto the shelf would also induce an offshelf component of bottom Ekman layer drainage which could assist movement of dense waters towards the shelf break, also promoting cascading. The hypothesis that sites favorable to cascading on the slope occur where isobaths strongly converge requires further investigation. In this regard, it is of interest to note that there is one further site on the Hebridean slope (just south of $59 \mathrm{~N}$ ) where similar constriction of the isobaths is found.

The fact that cascading occurs in winter, when standing stocks of phytoplanktonbiomass are low, means that its contribution to the off-shelf flux of organic carbon is unlikely to be important. For instance, assuming a cascade thickness of $50 \mathrm{~m}$ over an along-shelf-edge distance which could range from $5 \mathrm{~km}$ (the internal Rossby radius) to at most $200 \mathrm{~km}$ (the separation between UA and UC sections), downslope velocities of $0.02 \mathrm{~m} \mathrm{~s}^{-1}$ and a characteristic ratio of 50-100 $\mathrm{mg} \mathrm{C} / \mathrm{mg}$ Chlorophyll, the implied downslope carbon flux is 6-500 tonnes $\mathrm{d}^{-1}$ (Fig. 2f). The downslope Ekman drainage produced by the Slope Current could occur year-round, however, and may thus make a greater overall contribution to 
off-shelf fluxes of carbon. A further possible biological implication of cascading, particularly if it occurs earlier in the winter, is that it may provide a mechanism for the transport of the key copepod (zooplankton) species Calanus finmarchicus from the shelf to its deep over-wintering sites over the continental slope.

The indications from observations world-wide are that cascading is an intermittent process and in northwest European waters, where conditions for dense water formation are marginal in view of the mild climate, this is likely to be even more so. This is borne out by the fact that observations in the region of conditions favorable to cascading, let alone cascading itself, are exceedingly rare (Cooper and Vaux, 1949; Ljøen and Svannson, 1972). The present observations provide direct evidence for the hypothesis that cascading can occur at the European shelf edge and also provides some clues as to the shelf-edge locations which might be suitable for future targeted measurement programmes. The role of the poleward flowing Slope Current, both as a source of high salinity (dense) shelf-edge water and as a possible means of initiating cascading by driving off-shelf and downslope motions through Ekman drainage, has been highlighted. Overall, therefore, the present study broadens the parameter range world-wide of conditions under which shelf-edge cascading has been observed.

Acknowledgments. We wish to thank the UK Natural Environment Research Council - Research Vessel Services (RVS) for their support in the planning and execution of this cruise and extend particular thanks to Captain Mike Harding, the officers, crew and RVS technical support team of RRS Challenger. This work was funded by research grant GST/02/763 awarded under the NERC LOIS-SES special topic. GIS was supported by NERC grant GR9/01895, the Royal Society and grant 97-05-65635 from the Russian Foundation for Basic Research. This is LOIS publication number 318.

\section{REFERENCES}

Bignami, F., E. Salusti and S. Schiarini. 1990. Observations on a bottom vein of dense water in the southern Adriatic and Ionian Seas. J. Geophys. Res., 95, 7249-7259.

Booth, D. A. and D. J. Ellett. 1983. The Scottish continental slope current. Cont. Shelf Res., 2, 127-146.

Bowden, K. F. 1960. The dynamics of flow on a submarine ridge. Tellus, 12, 418-426.

Bryan, J. R., J. P. Riley and P. J. Le B. Williams. 1976. A Winkler procedure for making precise measurements of oxygen concentration for productivity and related studies. J.Exp. Mar. Biol. Ecol., 21, 191-197.

Cooper, L. H. N. and D. Vaux. 1949. Cascading over the continental slope of water from the Celtic Sea. J. Mar. Biol. Assoc. UK, 28, 719-750.

Dietrich, G. 1956. Überströmung des Island-Färöer-Rückens in Bodennähe nach Beobachtungen mit dem Forschungsschiff ‘Anton Dohrn' 1954/1955. Dt. Hydrogr. Z., 9,78-89.

Ellett, D. J. 1968. The cold 'winter water' of Rockall Bank. International Council for the Exploration of the Sea. Committee paper No. C.M. 1968/C:24.

Foster, T. D. and E. C. Carmack. 1976. Frontal zone mixing and Antarctic Bottom Water formation in the south Weddell Sea. Deep-Sea Res., 20, 301-317.

Gill, A. E. 1973. Circulation and bottom water production in the Weddell Sea. Deep-Sea Res., 20, $111-140$. 
Grasshoff, K. (ed.). 1976. Methods of seawater analysis, 2nd ed. Verlag Chemie, Weinheim.

Hill, A. E. 1995. Leakage of barotropic slope currents onto the continental shelf. J. Phys. Oceanogr., $25,1617-1621$.

Hill, A. E. and E. G. Mitchelson-Jacob. 1993. Observations of a poleward-flowing saline core on the continental slope west of Scotland. Deep-Sea Res., 40, 1521-1527.

Holligan, P. M. and S. B. Groom. 1986. Phytoplankton distributions along the shelf break. Proc. R. Soc. Edinburgh, 88B, 239-263.

Huthnance, J. M. 1986. The Rockall slope current and shelf edge processes. Proc. R. Soc. Edinburgh, $88 B, 83-101$.

-1995. Circulation, exchange and water masses at the ocean margin: the role of physical processes at the shelf edge. Progr. Oceanogr., 35, 353-431.

Jones, K., R. J. Gowen and P. B. Tett. 1984. Water column structure and summer phytoplankton distributions in the Sound of Jura, Scotland. J. Exp. Mar. Biol. Ecol., 78, 269-289.

Killworth, P. D. 1977. Mixing on the Weddell Sea continental slope. Deep-Sea Res., 24, 427-448.

Lavin, M. F., G. Gaxiola-Castro, J .M. Robles and K. Richter. 1995. Winter water masses and nutrients in the Gulf of California. J. Geophys. Res., 100, 8587-8605.

Lennon, G. W., D. G.Bowers, R. A. Nunes, B. D.Scott, M. Ali, J. Boyle, C. Wenju, M. Herzfeld, G. Johansson, S. Nield, P. Petrusevics, P. Stephenson, A. A. Suskin and S. E. A. Wijffels. 1987. Gravity currents and the release of salt water from an inverse estuary. Nature, 327, 696-697.

Ljøen, R. and A. Svannson. 1972. Long-term variations of subsurface temperatures in the Skagerrak. Deep-Sea Res., 19, 277-288.

Melling, H. and E. L. Lewis. 1982. Shelf drainage flows in the Beaufort Sea and the effect on the Arctic Ocean pycnocline. Deep-Sea Res., 29, 967-985.

Middleton, J.H., T.D. Foster and A. Foldvik . 1982. Low frequency currents and continental shelf waves in the Southern Weddell Sea. J. Phys. Oceanogr.,12, 618-634.

Nansen, F. 1913. The waters of the north-eastern North Atlantic. Internationale Revue der Gesamten Hydrobiologie und Hydrographie. Suppl . to Bd 4., 139 pp.

Nof , D. 1983. The translation of isolated cold eddies along a sloping bottom. Deep-Sea Res., 30, 171-182.

Price J.F. and M. O'Neil Baringer. 1994. Outflows and deep water production by marginal seas. Progr. Oceanogr., 33, 161-200.

Quadfasel, D., B. Rudels and K. Hirz . 1988. Outflow of dense water from a Svalbord fjord into Fram Strait. Deep-Sea Res., 35, 1143-1150.

Ranger, C. B. 1994. Determination of low-level nutrients in environmental water samples using flow injection analysis. American Environmental Laboratory, Part 4.

Shapiro, G. I. and A. E. Hill. 1997. Dynamics of dense water cascades at the shelf edge. J.Phys. Oceanogr., 27, 2381-2394.

Smith, P. C. 1975. A streamtube model for bottom boundary currents in the ocean. Deep-Sea Res., 22, 853-873.

Steele , J. H. 1959. Notes on the deep water overflow across the Iceland Faroe Ridge. Rapp . P.-v. Réun . Cons. Perm. Int. Explor . Mar, 149, 84-88.

Tomczak, M. 1985. The Bass Strait cascade during winter 1981. Cont. Shelf Res., 4, 225-278.

UNESCO. 1981. Tenth report of the joint panel on oceanographic tables and standards. UNESCO Technical Papers in Marine Science. No. 36. UNESCO, Paris.

Whitehead, J.A. 1987. Dense water off continents. Nature, 327, 656.

Zoccolotti,L. and E. Salusti. 1987. Observations of a vein of very dense marine water in the southern Adriatic Sea. Cont. Shelf Res., 7, 535-551. ${ }^{2}$

Received: 9 June, 1997; revised: 6 October, 1997. 